\title{
THE CHALLENGES OF RECONSTRUCTION AFTER THE OCTOBER 2005 KASHMIR EARTHQUAKE
}

\author{
Hamid Mumtaz ${ }^{1}$, S. Habib Mughal ${ }^{1}$, Maggie Stephenson ${ }^{1}$ \\ and Jitendra K. Bothara ${ }^{2}$ \\ This paper was presented at the NZSEE Annual Conference, April 11-13 2008 and has
been peer reviewed.
}

\begin{abstract}
The $8^{\text {th }}$ October 2005 Kashmir Earthquake was one the largest earthquakes in Northern Pakistan in its recorded history. It caused an unprecedented level of damage and destruction in Pakistan Administered Kashmir (PAK) and the North Western Frontier Province (NWFP). It damaged or collapsed more than 0.6 million buildings - leaving 3.5 million people shelter less as winter approached. A large part of the earthquake-affected area is difficult to access and highly snowprone, with rugged terrain and scattered settlements. It posed unique challenges and efforts on a massive-scale for reconstruction. For residential buildings, the Pakistan government adopted a house-owner driven approach. The reconstruction policy stated that the government and other agencies would provide equal technical assistance and subsidy to each family, without differentiating between who lost what. To increase capacity in earthquake-resistant construction, large-scale training of artisans, technicians, engineers, and community mobilisers has been conducted. Campaigns to "build back better" have raised awareness in the communities. Local Housing Reconstruction Centres have been established for training, advice, and dissemination of earthquake-resistant technology. This decentralised approach has helped in achieving reconstruction smoothly. This paper will present the authors' first-hand experience in the reconstruction effort, and the opportunities and unique challenges faced.
\end{abstract}

\section{INTRODUCTION}

An earthquake of magnitude 7.6 on the Richter scale struck Pakistan Administered Kashmir (PAK) and the North Western Frontier Province (NWFP) of Pakistan (Figure 1) on the morning of 8 October 2005. The earthquake was spread over an area of approximately $28,000 \mathrm{~km}^{2}$ across three districts of PAK and five districts of NWFP. The fatalities and destruction made it by far the most fatal earthquake ever to occur in the Indian subcontinent or its surrounding plate boundaries (Bilham, 2005). It killed more than 73,000 people and injured 128,000 .

The earthquake damaged or destroyed more than 600,000 houses, 6,298 education institutions and 782 health facilities in the NWFP and PAK. Eighty-four percent of the total housing stock was damaged or destroyed in PAK, and 36 percent in the NWFP. Ninety percent of the destroyed or damaged housing was in rural areas (ERRA, 2006). By far the private housing sector suffered the most extensive damage, followed by the transport, education, and agriculture and livestock sectors.

Poor performance of the buildings is to blame for the catastrophe, though performance of traditional building types such as Dhajji-dewari and Batar performed far better than their modern counterparts. Buildings performed poorly because of very weak construction materials such as dry stone, stone in mud mortar; or were constructed very poorly despite being of good materials such as fired brick or stone in cement mortar, confined masonry, and reinforced concrete. Probably more than $95 \%$ of buildings in the earthquake-affected area were non-engineered, and almost all buildings were without any aseismic features. While artisans clearly lacked knowledge of aseismic construction, so did the engineers and technicians. The authors believe that the major problem was the overall failure to appreciate that the region is earthquakeprone, despite there having been a history of earthquakes, and despite recent studies also showing the potential of major earthquakes in the region (Bilham, 2001). It was a classic case of total failure of knowledge dissemination on earthquake-resistant construction and the need for it. Furthermore, there is no strong local tradition, perhaps due to the infrequency of earthquakes, that led to the loss of skills in traditional construction such as the use of through-stones in stone masonry.

The destruction brought about an unprecedented level of challenge for the reconstruction, especially because of the extensive, rugged terrain - many areas are very remote and inaccessible, and prone to extremely bad weather, particularly during winter. Other major issues included the lack of knowledge on earthquake-resistant construction, manpower shortages, socio-cultural issues, a building production mechanism which is very informal and incremental in nature, a lack of accessibility to (and acceptability of) the formal sector, a lack of preparedness, and the scale and extent of reconstruction required. This paper focuses on these challenges and the strategy adopted. While it covers only PAK and the NWFP, the earthquake caused human casualties, building damage and economic loss in Indian-administered Kashmir as well.

\footnotetext{
${ }^{1}$ UN-HABITAT, Islamabad, Pakistan

${ }^{2}$ Beca Carter Hollings Ferner Ltd, Wellington, New Zealand, (Member)
} 


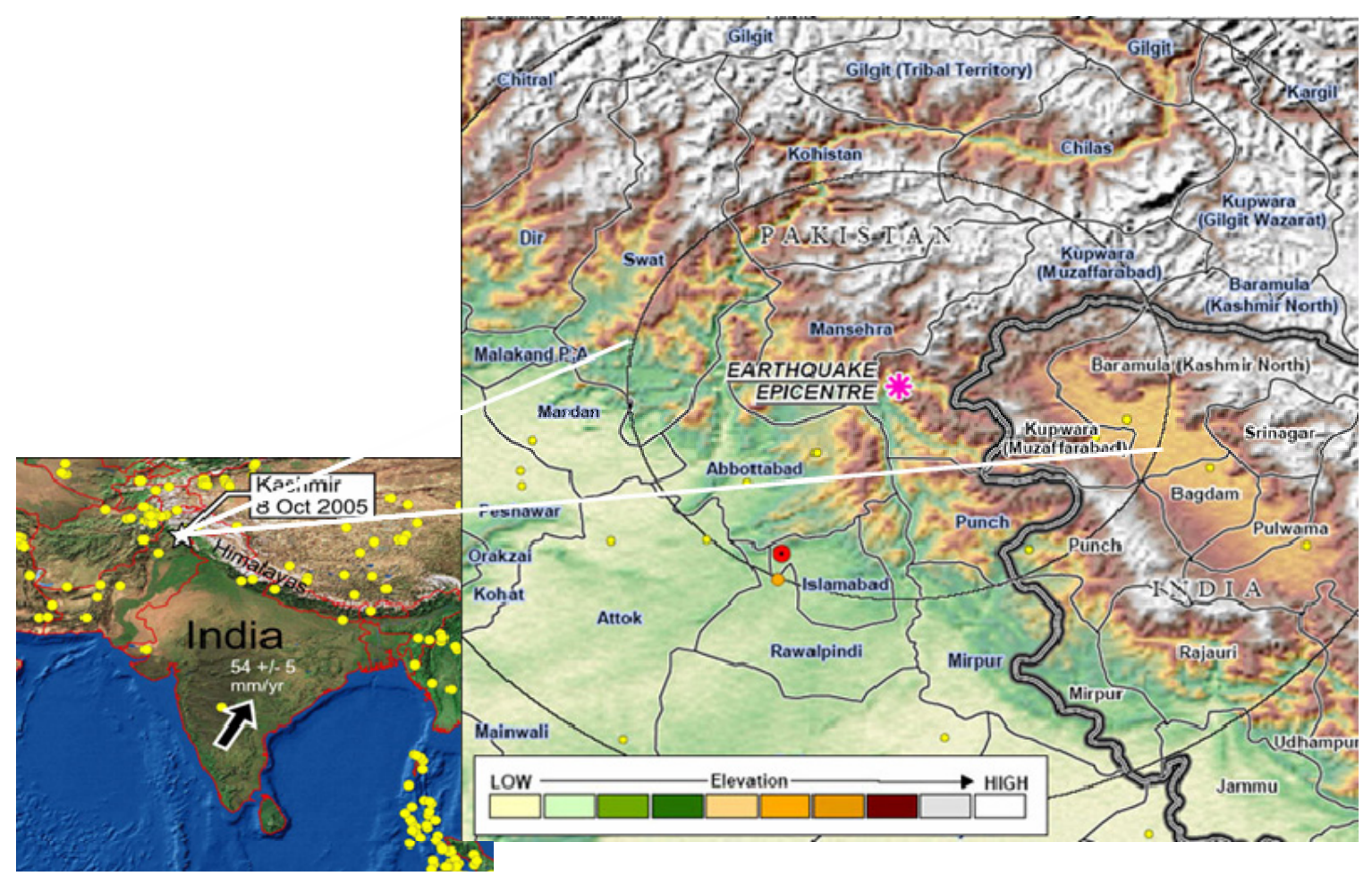

Figure 1. The earthquake-affected area.

\section{BUILDING MATERILAS AND TYPOLOGY}

The common construction materials are stone, fired brick, mud, steel and concrete, and timber. Overall, stone is the most common building material because of its local availability and affordability. Next to dry stone masonry, the most common binder material for masonry construction is mud. The selection of building materials is largely controlled by local availability, affordability, the local economy, and local climatic conditions. Many of the earthquake-affected areas are prone to heavy snowfalls that require thick walls and heavy insulation to keep out the extreme weather. The most common type of building types are discussed below.

The building production mechanism in the area is highly informal and incremental in nature, and engineers have hardly any say in the design of private buildings. Professional advice is rarely sought (even in urban areas) and, if sought for private houses, is mostly limited to the building permit process. Approximately $95 \%$ of the buildings in the area are nonengineered, and even the engineered ones are not much better than the non-engineered ones.

Design and construction in the area is mostly procured by the owners themselves, employing a local skilled artisan to direct operations. The traditional artisans play a pivotal role in the overall construction activity, and the owner relies on them heavily for all types of advice. The artisans provide overall technical and organizational support - even though none of them has formal training. Furthermore, construction of these buildings is largely dictated by the local availability of construction materials and skills. The owners procure the materials themselves, according to the quantities advised by the mason, and are therefore responsible for material quality selection.

Governmental buildings or large construction projects are developed and constructed more formally. However, these also clearly showed conceptual deficiencies and lacked quality control in their construction. The poor quality of construction, even of engineered buildings, was one of the major reasons for the catastrophe (Bothara, 2007). Tragically, 18,000 school children and 1,800 teachers died in schools.

The construction materials and skills are extremely deficient in the area, particularly with respect to the modern materials. The steel observed in the area was of an extremely low grade, with all possible deficiencies such as high brittleness and flakiness. Hand mixing is the most common method of concrete preparation, and concrete vibrators are rarely used for compaction - resulting in low-grade, honeycombed concrete. Curing of concrete is still not practised as an integral part of the concreting process. The concrete blocks are of poor quality because of the poor quality of the concrete, a lack of compaction and very little or no curing.

\subsection{Stone masonry building}

Stone masonry (and its variations) is the most common building type in the area. The walls of these buildings are constructed of boulders, rubble stone, or dressed/semi-dressed stones in mud, lime or cement-sand mortar. Dry stone and mud-mortared construction is more common in rural areas and old settlements where affordability is less and accessibility to modern materials is a little difficult. If dry stone or mud is used as mortar, the roof is usually a heavy mud one, or of light corrugated iron sheet on a timber frame. If cement mortar is used, the common roof types are reinforced-concrete slabs and light metal on timber trusses. However, these classifications blur with time and space, affordability, and accessibility. Furthermore, after the earthquake the situation has significantly changed because of the distribution of corrugated iron sheets and government assistance. Cement-based mortar is more common in urban areas, market centres, and along the main transport corridors. These buildings are up to three storeys high. Mud-based mortar houses are sometimes two storeys high, although the common height is one storey in rural areas. Floors are constructed of timber of very large sections overlain by mud or reinforced concrete. Cement mortar is usually very weak and can be crumbled with the 
fingers. Mixing of wall materials is also common. Internal walls may be in brick or block, and external walls in stone - or a part of building may be of stone and another of concrete. The particular problems of dressed-stone construction are the small, square sizes of the stones, no through-stones, and loose gravel fill in the centre of the walls leading to delamination. Field-stone work was better than the dressed-stone work of formal buildings.

A few indigenous earthquake-resistant building types were observed. These include Dhajji-dewari ("Dhajji"), Batar and

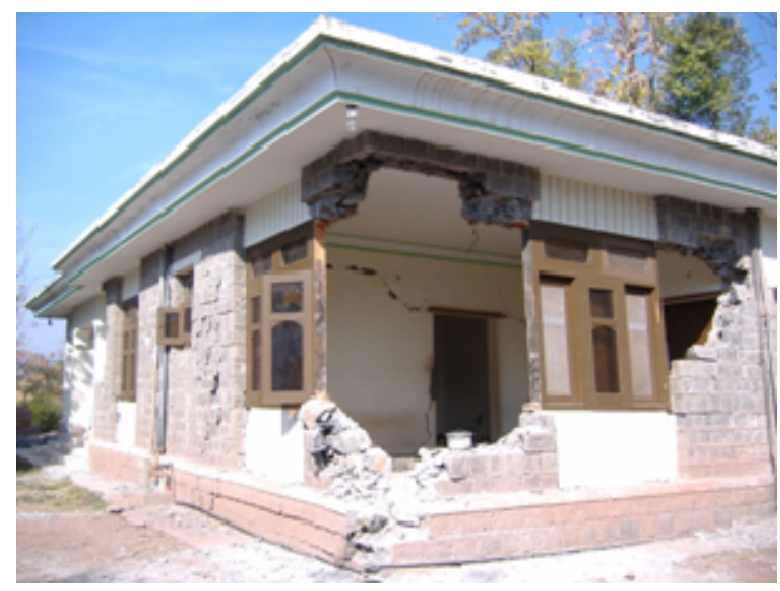

a) A modern stone masonry building
Beetar (Figure 3). Dhajji performed extremely well. The performance of Batar was a little inferior because of the large distances between timber bands, the use of short pieces of wood, a lack of cross timbers, and problems with joints. Despite their relatively better performance, these building types are slowly becoming obsolete because of the lack of wood and the attraction of modern materials - although the use of Dhajji has been revived after the earthquake.

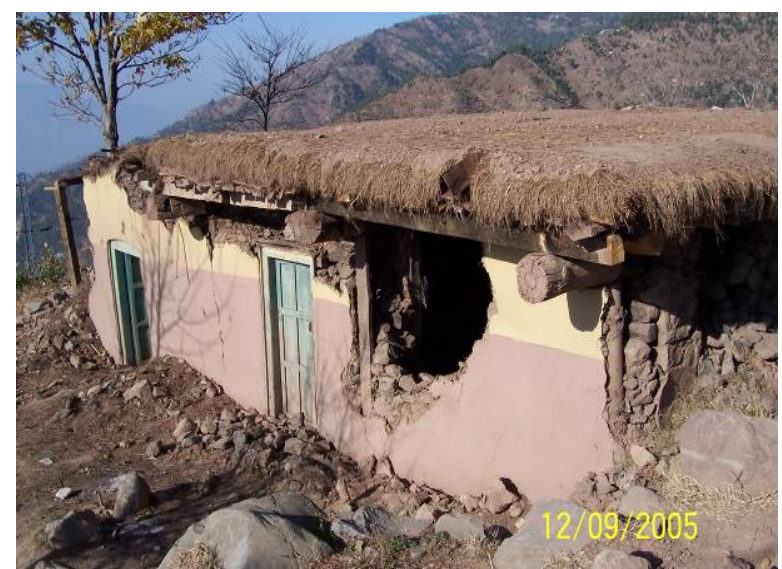

b) A traditional stone masonry building

Figure 2. Typical stone masonry buildings.
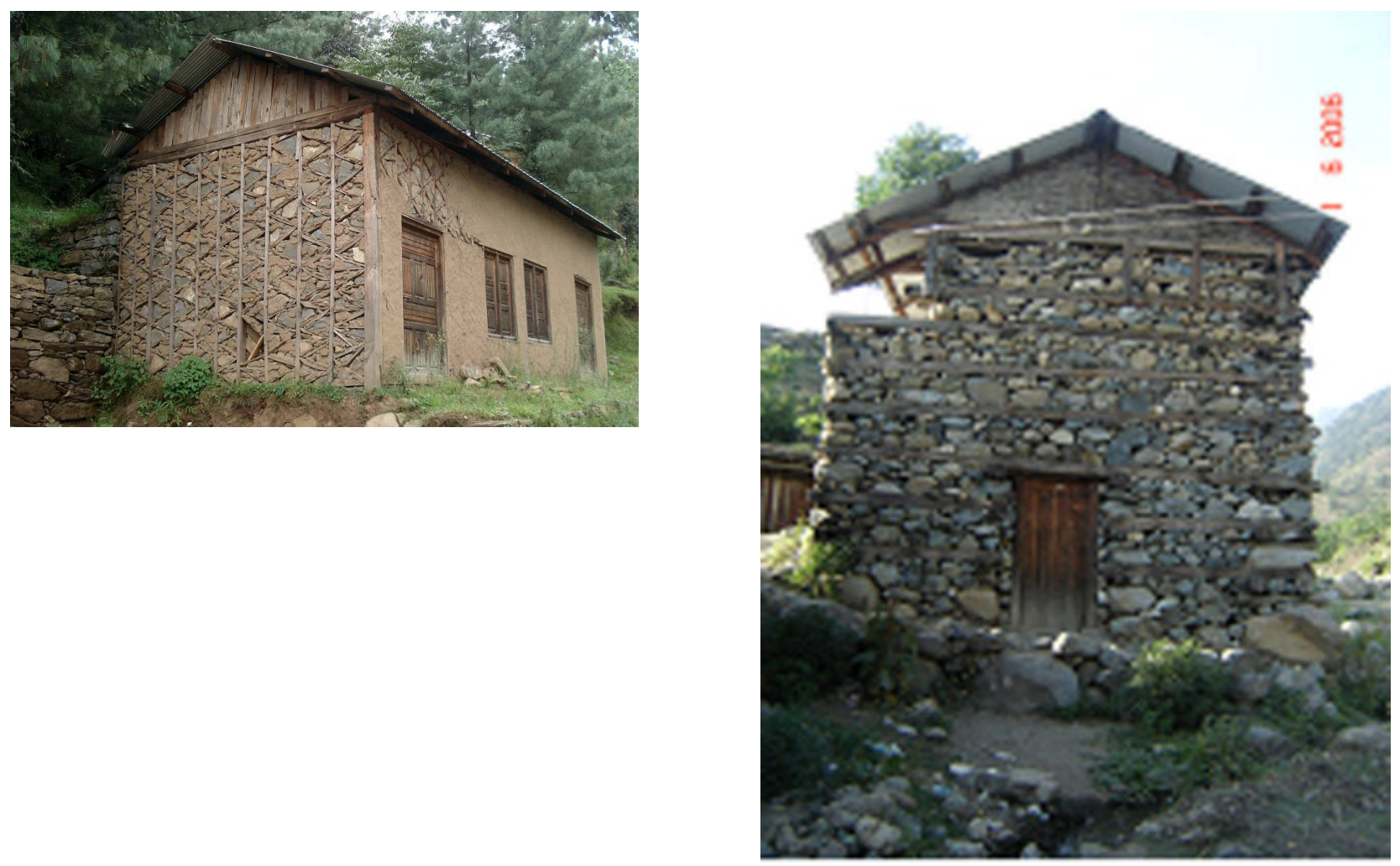

a) Dhajji-dewari (survived earthquake)

\section{b) Batar (survived earthquake)}

Figure 3. Excellent performance of traditional stone masonry buildings.

\subsection{Unreinforced concrete block masonry buildings}

The next most common construction material for walls is 150 to $200 \mathrm{~mm}$ wide solid concrete block in cement-sand mortar.
Hollow concrete blocks were not common. This could be because these require much more stringent quality control than is available there. The building height is limited to two 
storeys. The foundations of these buildings are mostly constructed of stone masonry, and the floors and roofs are usually reinforced concrete cast in situ. However, corrugated iron sheet roofs on timber structures are also very common, more common than reinforced concrete ones. These are relatively new construction types in the area. The quality of blocks is usually poor. These buildings are more common where accessibility is easier and sand and aggregates are abundant. limited to government construction, and for affluent people. These buildings are common in urban areas and market centres along the main roads. The walls of these buildings are constructed of brick in cement-sand mortar. The walls are usually 230 to $350 \mathrm{~mm}$ thick, although people have started to use $110 \mathrm{~mm}$ thick walls after the earthquake. The roofs and floors are usually cast-in-situ, reinforced concrete slabs. Foundations are mostly of stone masonry. These buildings are usually limited to two or three storeys.

\subsection{Unreinforced brick masonry buildings}

Bricks are not that common because these have to be transported from the distant plains. Therefore, they are mostly

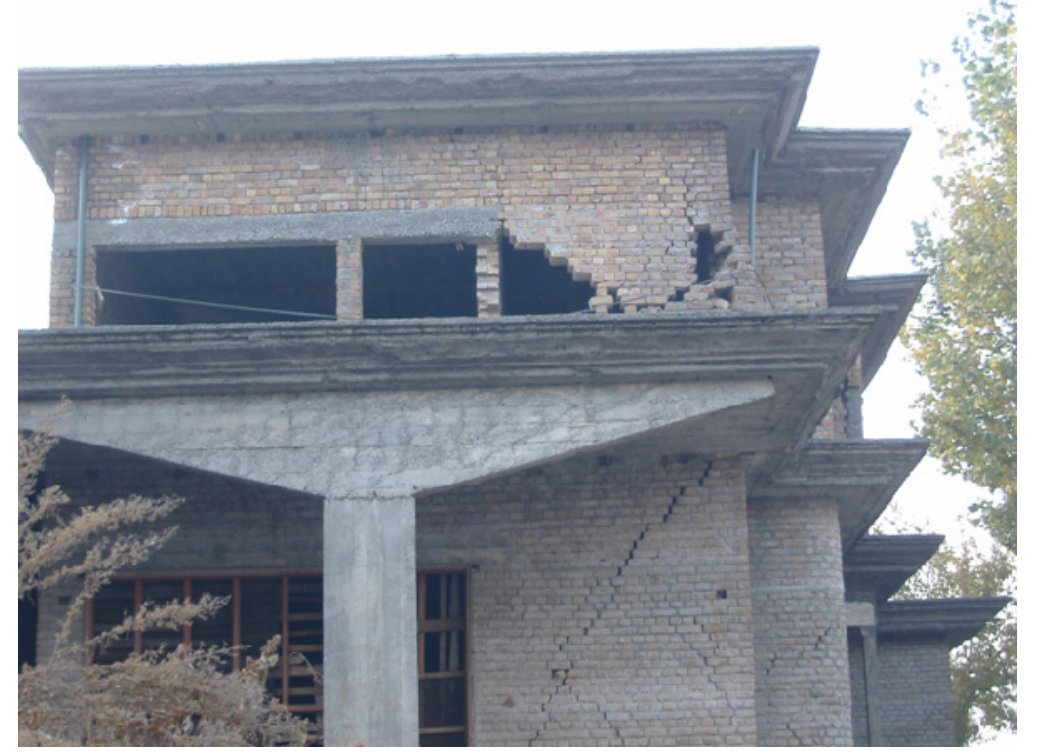

Figure 4. A typical brick masonry building.

\subsection{Reinforced concrete frame construction}

These buildings are usually up to five or more storeys high. The roofs and floors are typically cast-in-situ reinforced concrete slabs. Invariably, the cladding and partition walls are constructed of concrete block, brick, or stone masonry. The partition walls are usually a half brick thick $(110 \mathrm{~mm})$ or a block (150 or $200 \mathrm{~mm}$ ) thick, and are neither tied into the frame nor reinforced. These infilled frames suffer from poor configuration, detailing, materials and workmanship problems.

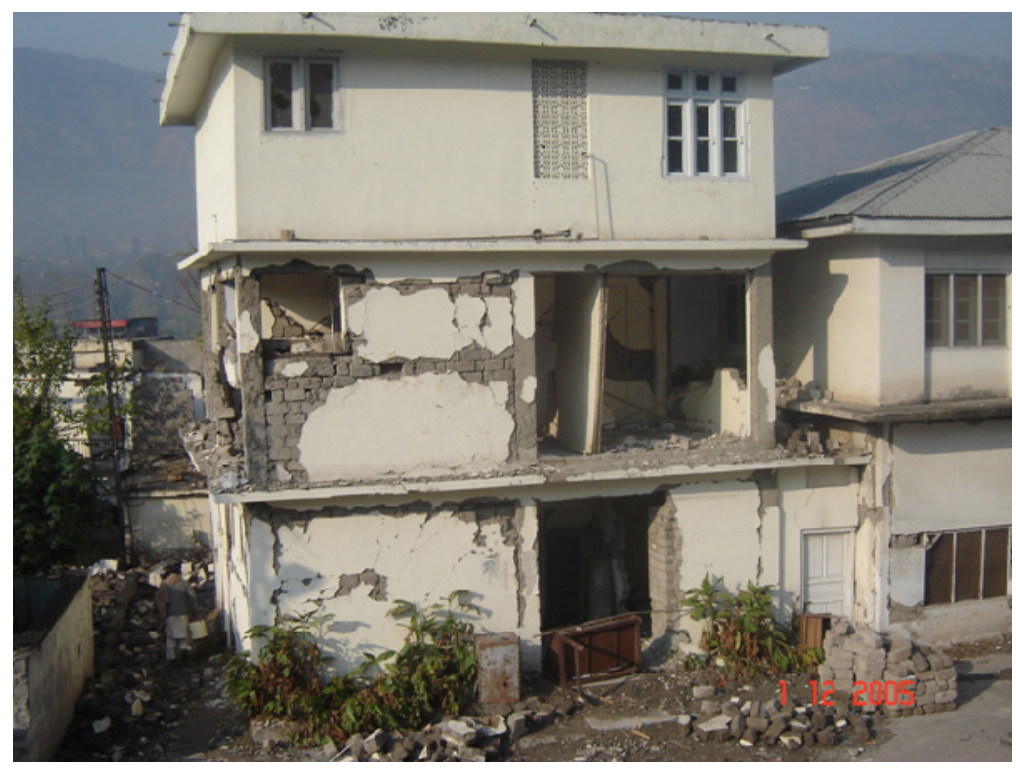

Figure 5. A typical reinforced concrete frame building with concrete block infill wall. 
A significant change in construction materials and building types has been observed after the earthquake. This is because of time and economic pressures, increasing material costs after the earthquake, and financial and material support (such as corrugated iron sheet as part of relief) from the government.
In many instances, people adopted hollow concrete block to replace stones as these were cheap and helped rapid construction (Figure 6). In other instances, people opted for hipped metal sheet roof that they got as relief - replacing flat earth roofs.

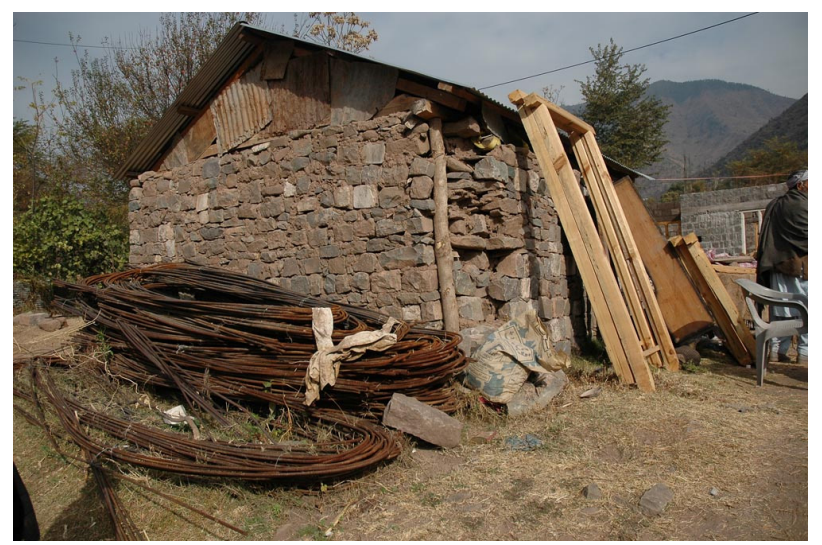

a) A stone masonry building with light timber frame, damaged by earthquake.

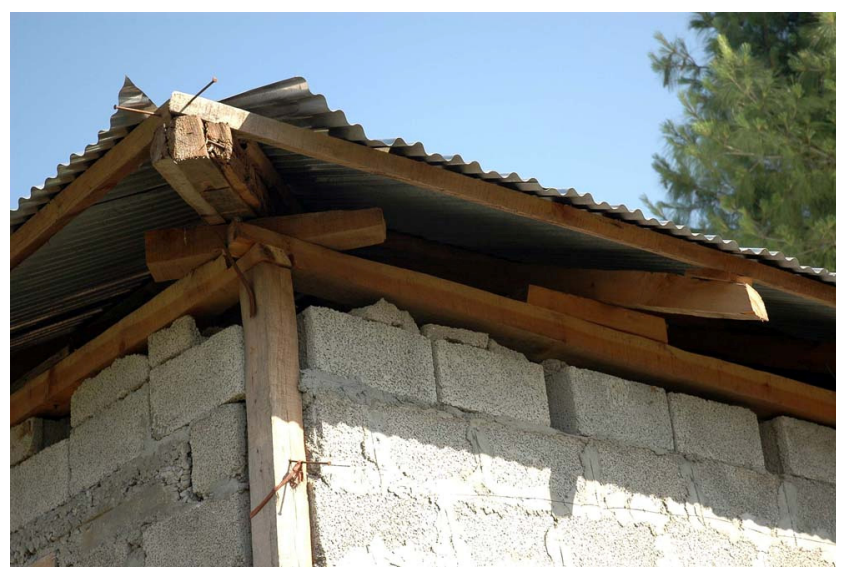

b) A block masonry building with light timber frame constructed after earthquake (note change in walls after earthquake).

Figure 6. Changing building types.

\section{DIAGNOSIS OF DISASTER}

\subsection{Seismic performance of building}

All the types of buildings discussed above, irrespective of construction materials or process, performed very poorly. Engineered buildings performed relatively better compared to the non-engineered ones because of better materials and the little bit of engineering input. However, these also performed at a far less than satisfactory level. Stone buildings suffered delamination of wall wythes, out-of-plane failures, shear failure of walls and disintegration of floor and roof. Most of these buildings just turned into a heap of materials because of a lack of integrity between structural components.

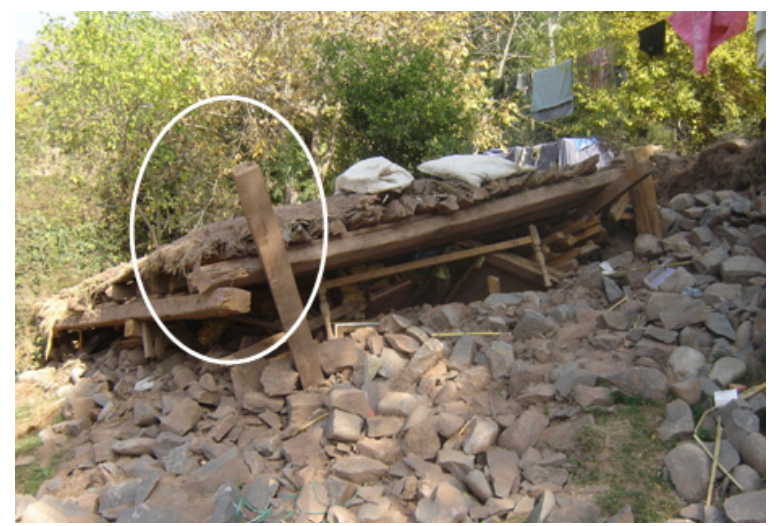

Figure 7: Continued on next page. a) A heap of materials.
Interestingly, a few of the local building types such as Dhajji, Beeter and Batar performed better than their modern counterparts such as reinforced concrete framed, and block or brick masonry buildings. Similarly, brick and block masonry buildings suffered out-of-plane failures and shear failure of walls. Reinforced concrete frame buildings suffered out-ofplane collapse and severe in-plane shear damage of walls; shear failure of columns and beams, lapping failure of reinforcement, anchorage failure of beam bars, opening of stirrups, cold joints and crushing of concrete (Bothara 2007). A few of these damage patterns are presented in Figures 2, 4, 5 and 7.

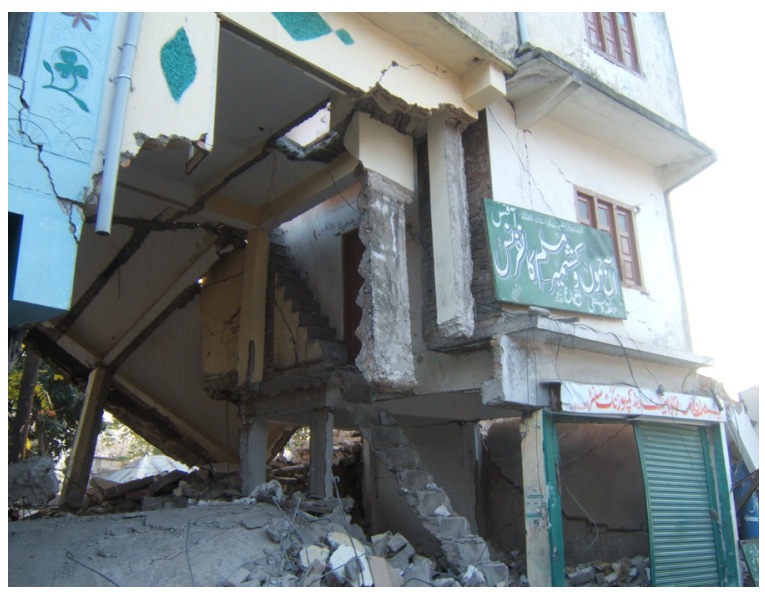

b) Reinforced concrete frame building on top of masonry building. 

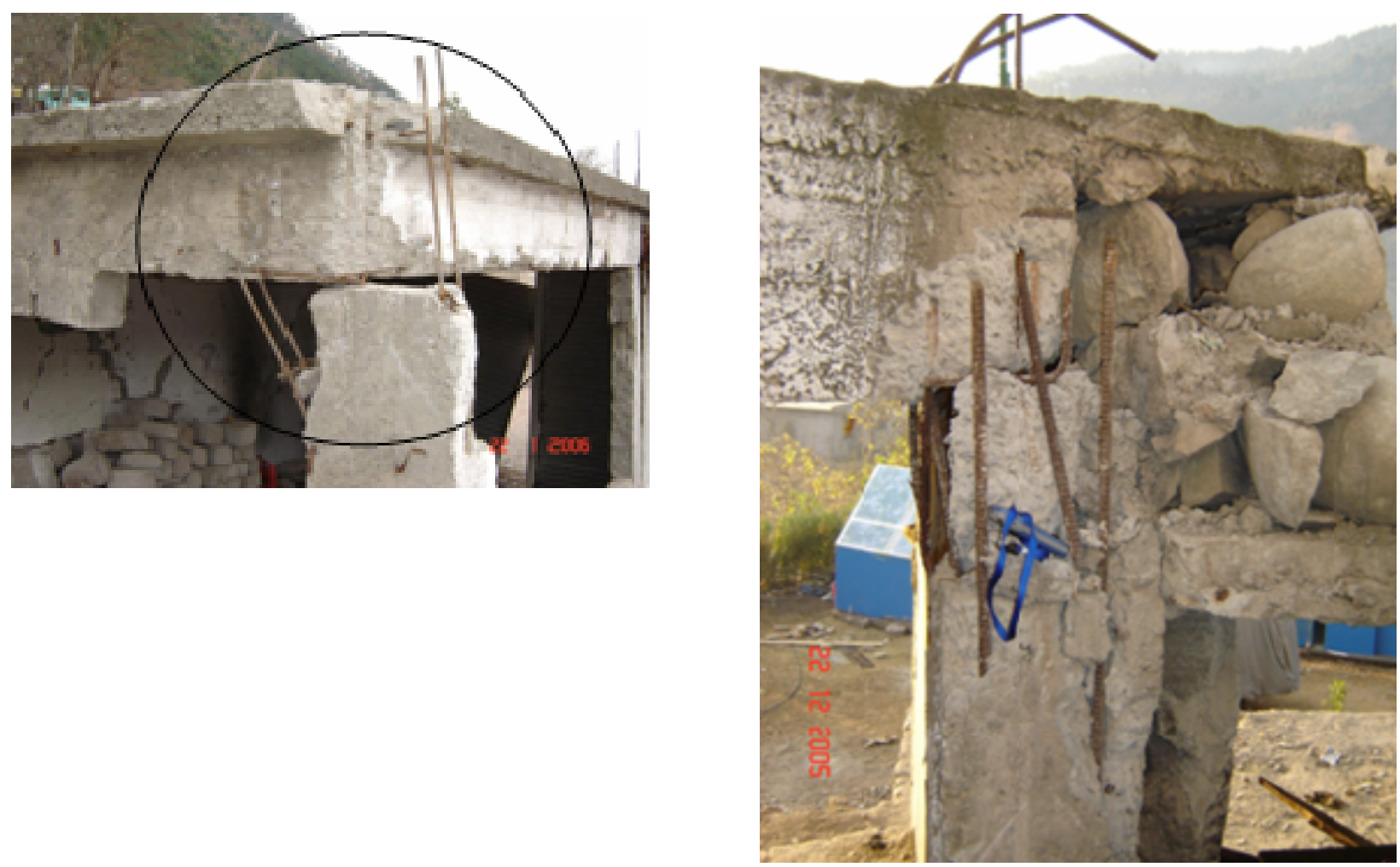

c) Cold-joint problem.

d) No stirrups in column.

\section{Figure 7. Typical failure modes of reinforced concrete frame buildings.}

Observations of damage showed that many buildings suffered catastrophic destruction or damage because of very minor deficiencies which could have been easily avoided. . The authors believe that, had there been even the smallest awareness of proper construction methods, a minor input in building construction practices, the magnitude of the disaster would have been far less than what was observed.

\subsection{Major factors that contributed to the disaster}

The building damage and/or destruction was the major contributor to human and property loss. The buildings in the earthquake affected areas were completely inappropriate for a seismic region because of poor materials and the construction processes as discussed above. It appears that more than $90 \%$ of human deaths were caused by the buildings themselves.

A few factors that contributed to this disaster are: lack of appreciation of seismic hazard, fatalism, the building production mechanism, the lack of a techno-legal regime to address the safety issues, access to information, weak local economy, affordability and accessibility to better materials and technology; knowledge gap on earthquake resistant construction at all levels; lack of local availability of better materials or their improved use, quality control issues, poor maintenance, loss of traditional skills and ignorance or negligence on quality issues in construction (Bothara, 2007).

\section{RECONSTRUCTION CHALLENGES}

- Inaccessibility: The earthquake area is spread over 28,000 square kilometres and is mostly in very rugged, high altitude, snow-falling terrain that is remote and with low accessibility. It is so spread out that, in some cases, it takes over 12 hours by road to travel from one end of the affected district to the other. To reach many of the villages at high altitude, it takes another day from the nearest road. Many of the areas are totally cut off during winter months by snow. The terrain makes transporting construction materials an impossible task in most of the area. The earthquake-affected districts have few towns - the majority of the population lives in rural areas. Over $90 \%$ of the 600,000 homes destroyed and damaged are rural houses which are, in many cases, very sparsely distributed. This makes it extremely difficult for any outside help to be delivered.

- Infrastructure for reconstruction: This earthquake caused wholesale and widespread impacts, and existing governmental and non-governmental machinery to be defunct. Unlike the concentrated damage at Bam (Iran), or in tsunami-affected communities where a few miles inland there is no destruction so support is available, all of Kashmir was simultaneously disabled by the earthquake. All government offices and officials, NGO offices and staff, infrastructure and communications were affected. Every household was in shock - through loss of life, injuries or loss of homes. Every household was struggling to cope with immediate concerns.

The scale of the catastrophe and the timing before the onset of severe winter conditions meant that the relief effort was vast, and continued for several months just to meet basic needs of food and shelter. Many international NGOs were committed to post-tsunami reconstruction elsewhere, the national NGO sector was weak and also affected by the earthquake, and the capacity to provide relief was low. The Pakistan army played a major role in relief, but was also affected. The capacity among the humanitarian community to plan for or support reconstruction was very low. 
- Lack of preparedness: One of the major challenges was that of bringing a whole, new machinery on board for reconstruction because of the inexperienced set of government officials (few are experienced for this scale of disaster), consulting engineers, young field engineers, masons, and the community. After the earthquake, everyone was in shock and facing the dilemma of "What next?". When one of the authors visited the area with a team of engineers, six weeks after the earthquake, for capacity building for reconstruction, he was virtually told by everyone that it was too early to think of reconstruction, there being no people available for the training activity. It took him two weeks to convince that all needed to start thinking of reconstruction.

- Loss of faith: In October 2005, and for many months afterwards, fear prevailed. Aftershocks continued frequently for six months. Some people moved away from their land. Most would not sleep in any of the remaining buildings, preferring tents even in the winter. Their greatest fears were of stones and heavy roofs. Many threw away good stone from their houses as rubble, but salvaged the timber from their roofs for use in shelters or for future, lighter roofs. As the earthquake had also destroyed many reinforced concrete frames, many people felt there was no good building technique. It was extremely difficult to convince them that it was not the earthquake, but the poorly constructed buildings that caused the disaster and that buildings can be made earthquake-safe. The authors saw evidence of demolition of many damaged buildings because the house owner had lost the faith in the building's strength, even though the building could have been easily repaired and strengthened.

- Building construction: The building construction mechanism is mostly vernacular, non-formal, incremental in nature, and dictated by local availability of construction materials. The engineering community does not know much about these construction types. The building practices vary rapidly with changes in local availability of materials, culture, and economic status of the building owner. Thus, it is neither possible to strictly standardise everything, nor would it be appropriate.

- Manpower shortage: It was predicted that the reconstruction effort would require some 60,000 skilled manpower that included engineers, foremen, masons, and carpenters - and another 80,000 semiskilled/ unskilled workers. Developing manpower on this scale is in itself a mammoth task. The World Bank's Damage and Needs Assessment in 2005 estimated that only $20 \%$ of the needs could be met from within PAK. Therefore, the phenomenon of migrant labour and the need to also train and inform them was identified from a very early stage.

- Knowledge gap: The construction workforce, in general, lacked knowledge of earthquake-resistant technology because it has never been considered an integral part of general engineering education in Pakistan. Moreover, construction artisans in the area are not formally trained. Their skills are passed down from generation to generation, or learnt from other masters. Of course, a small number of craftsmen who have worked in the Gulf states or on the plains of Pakistan have got better experience in steel fixing, concrete, etc. Without formal training, newer techniques for use with modern materials are not being introduced to craftsman and technicians. Technology dissemination is considered complete once it reaches the professional engineering community and mid-level technicians. Furthermore, the academic institutions appear to be apathetic towards both non-engineered materials and traditional technologies. They depict them as an obsolete and unsafe option, although these will still govern the future, and there exists quite a number of traditional construction typologies that have stood their ground against severe earthquakes (Figure 3). The implication was that, despite excellent performance of these building types, initially these were prevented from being options for reconstruction on the grounds that these are stone buildings constructed with mud mortar.

- Limited options for rural reconstruction: Due to both the lack of knowledge and the attitude of the formal construction industry towards traditional materials and technology, very few options were available at the beginning of rural reconstruction where local materials dominate. The engineering sector pushed cement and steel-based construction which was not viable from economic or accessibility points of view.

- Lack of awareness: Although the area is highly seismically active, and there is history of large earthquakes in the area, there is a severe lack of awareness at all levels of society. This lack of awareness is because of the infrequency of earthquakes.

- Techno-legal regime: There does not exist an effective building monitoring and site enforcement mechanism for building design and construction - even in the urban areas, let alone in the rural ones.

- Access to information: Most of the area affected by the earthquake is remote from modern information systems, and people there lack information on better construction even though they desire to know. Immediately after the earthquake, there was largely a vacuum of the necessary materials. The people, including the government machinery, were greatly confused.

- Economics: A large proportion of the population is economically disadvantaged. They do not have access to or can afford modern materials such as cement and steel. Furthermore, the cost is exacerbated by transport costs.

- Socio-cultural issues: The community is highly fatalistic, and earthquakes are considered to be God's way of punishing sinners. This did not let people think about the causes of disaster and possible mitigation options. Furthermore, earthquake safety is not only a technical problem, but is also a socio-cultural and economic issue that has a lot to do with one's faith, religion, fatalism, interpretation and understanding of natural phenomenon, and affordability. Without understanding these issues, earthquake safety cannot be implemented in a sustainable way. However, the formal sector largely lacked this understanding. 


\section{RECONSTRUCTION STRATEGY INSTITUTIONAL FRAMEWORK}

To coordinate the earthquake reconstruction and rehabilitation of the earthquake devastated areas in PAK and the NWFP, a Reconstruction and Rehabilitation Authority (ERRA) has been set up by the Government of the Islamic Republic of Pakistan.

Seeing the mammoth task of reconstruction and challenges posed, ERRA developed a comprehensive policy for reconstruction and rehabilitation. ERRA recognized that the interventions in rural areas would not be those suitable for urban areas because of the diverse socio-economic regimes in rural areas, their restricted accessibility to materials, technology and information, and the state's lack of capability to administer the laws, enforce compliance with building codes, force submission of plans to the relevant local authority, and undertake building inspections. They therefore developed a different strategy for reconstruction. The basic focus was to "build back better" with house-owner driven reconstruction under assisted and inspected construction by government through partnering organisations. Their strategy envisages a community-based approach that shares the responsibility amongst as many qualified partners as possible for reconstruction. The salient features of the reconstruction policy are discussed below (ERRA, 2006):

- House-owner driven reconstruction strategy: the policy puts special focus on house-owner driven reconstruction with prior training, information dissemination, and education and communication campaigns. It advises rebuilding with familiar methods and easily accessible materials (ensuring sustainability and cultural preferences in design); providing technical assistance during construction; use of self labour and salvaged material; additional resources such as hired trained craftsmen; and ensuring building materials supply chains.

- Ensuring seismic safety: The policy puts special attention on incorporation of seismic safety in building construction through a review and approval mechanism for construction guidelines, structural designs, and training curricula, and through the development of reference minimum structural design standards that meet internationally-accepted requirements for low-cost earthquake-resistant housing.

- Assisted and Inspected Reconstruction: To assist the reconstruction, implementation of seismic safety in construction, and proper quality control, it requires mobilisation of a large number of assistance and inspection (AI) teams for house-to-house advice, and subsequent inspection to certify the house as compliant for ERRA to disburse cash grants in tranches through the banks. In the majority of the affected areas, the AI teams consist of Pakistani Army personnel from the Engineers Corps with designated community representatives such as teachers. In a smaller number of union councils, the AI teams consist of technical and community representatives from the Pakistan Poverty Alleviation Fund (a very large semigovernment organisation which has been working for many years in the area). UN-HABITAT provides training for all AI teams. From January 2008, the Pakistan Army AI teams are to be directly supported in the field by UN-HABITAT engineers to resolve noncompliant cases through joint technical assessment and a referral system.

- Uniform assistance packages: It sets a uniform policy for financial grants and technical support, throughout the earthquake-affected areas. It offers a uniform financial assistance package for rebuilding to all those affected. Uniform technical assistance is based on a model of one partner organisation operating in (and responsible for) each Union Council (approximately 25,000 people). The partner organisation has technical and social mobilisation staff in multiple mobile teams delivering information, advice and assistance at village level. The teams include artisans supported by engineers. Partner organisations are supported at district level by Housing Reconstruction Centres (HRC) operated by UN-HABITAT. The HRC are focal points for training, technical support, information, advice, research and development. UNHABITAT also acts as a partner organisation - directly implementing in 36 Union Councils. There are no donor-built houses for individual beneficiaries, and thus none of the resulting difficulties in expectations, dependency, inappropriate imported models, and arbitrary or unaccountable selection of beneficiaries. There are no variations between the official technical or financial assistance each beneficiary household is eligible to receive.

To meet its policy objectives and to smoothen the reconstruction activity, ERRA has developed a comprehensive institutional framework (Figure 8). Its objective is to make house owners responsible, and to inculcate a culture of mitigation. In this regard, it is really working.

The eight HRCs are the focal point for training and information dissemination. They provide regular technical assistance to building owners, check the reconstruction activity, and support the NGOs working on reconstruction. Their field presence also allows them to monitor reconstruction progress, carry out research and development, and contribute to policy and advocacy. 


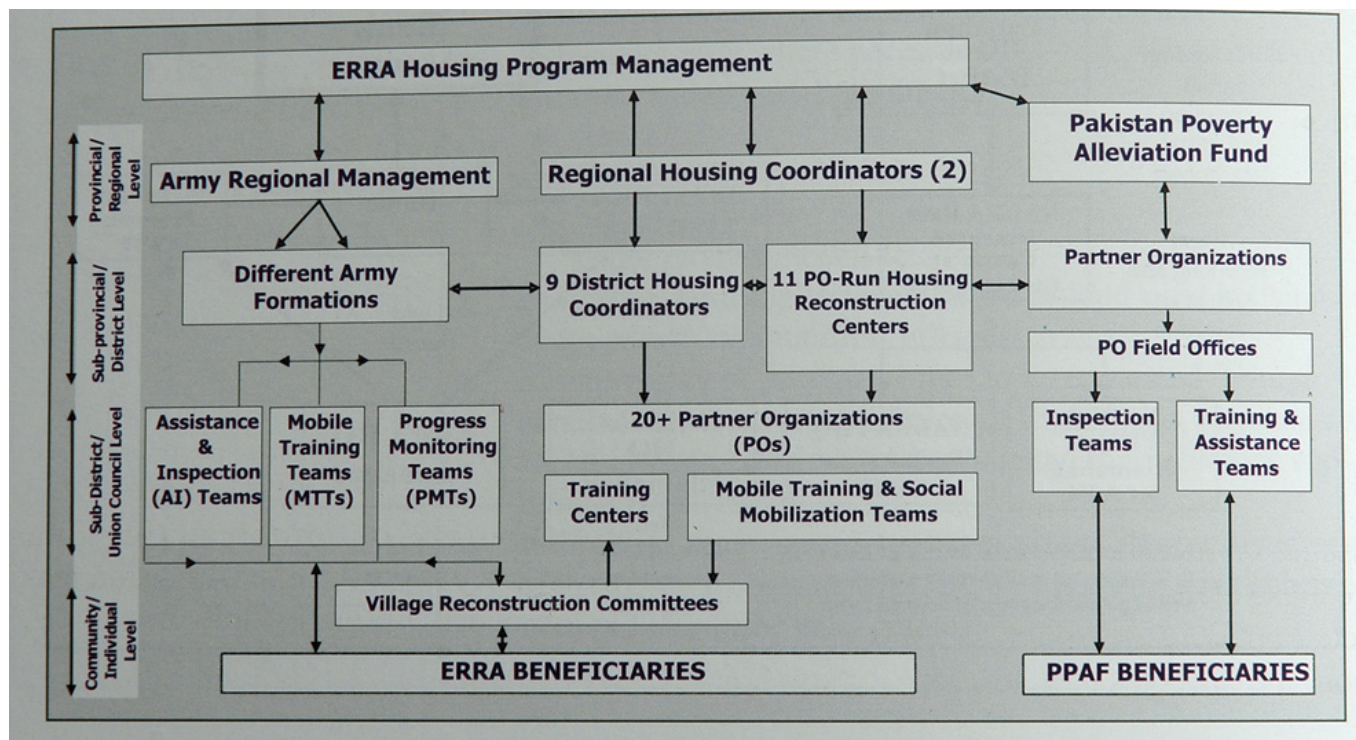

Figure 8. Institutional framework for the housing strategy (ERRA, 2006).

\section{RECONSTRUCTION ACTIVITY}

\subsection{UN-HABITAT}

UN-HABITAT operates in Pakistan in support of rural housing reconstruction from the federal level to the village level. In Islamabad, they actively work in partnership with ERRA, NESPAK, the World Bank, SDC, PPAF and other technical interests in policy development, and in the progressive development of technical standards and information materials. In the Union Councils in PAK, they have a team of over 400 staff (expanded from 100 in 2006) working closely with households, communities, and construction stakeholders.

\subsection{Capacity-building in aseismic construction and the} cascade effect

In the early stage of the recovery, the National Society for Earthquake Technology-Nepal (NSET) was invited by the UN Development Programme (UNDP) to assist in Pakistan. Help was requested for capacity building of local engineers, technicians, craftsman, contractors; construction of demonstration buildings; and undertaking of awarenessraising programmes for aseismic construction that were later extended by UN-HABITAT. A few other organizations (such as GOAL, Swiss Development Cooperation, Pakistan Poverty Alleviation Fund, Pakistan Army, Mercy Corps, Islamic Relief, IFRC, National Rural Support Programme, Shelter for Life, Aga Khan Development Network) also worked for capacity building of local building stakeholders. NSET's activities developed master trainers for the sustainability of the programme, and created posters, manuals to facilitate the reconstruction process with UN-Habitat partners. The master trainers later become resource persons for UN-Habitat. These master trainers are now involved in capacity building of other stakeholders in reconstruction and recovery programmes. These include the army's AI teams, sub engineers, social mobilisers, Village Reconstruction Committee (VRC) members, building owners, craftsmen, and construction professionals from community-based organisations (Figure 9).

\section{CASCADE OF TRAINING}

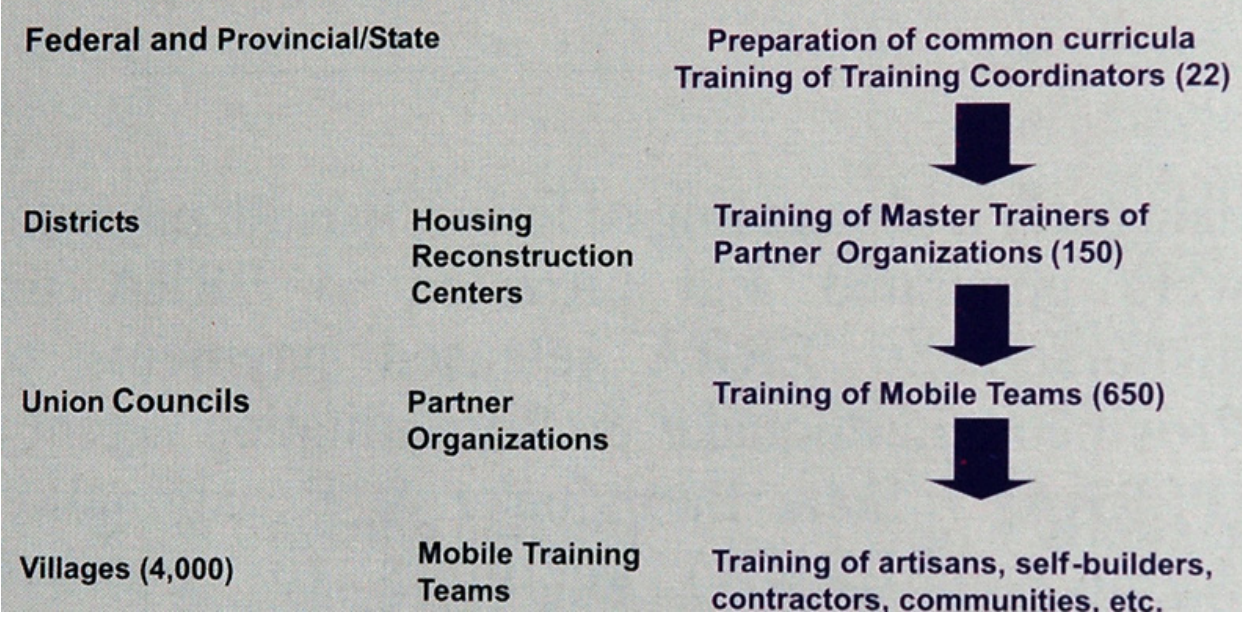

Figure 9. Cascade of Training. 
The training covered basic technical skills for assessment and inspection, community mobilisation, and aseismic construction (Figure 10). These professionals are further

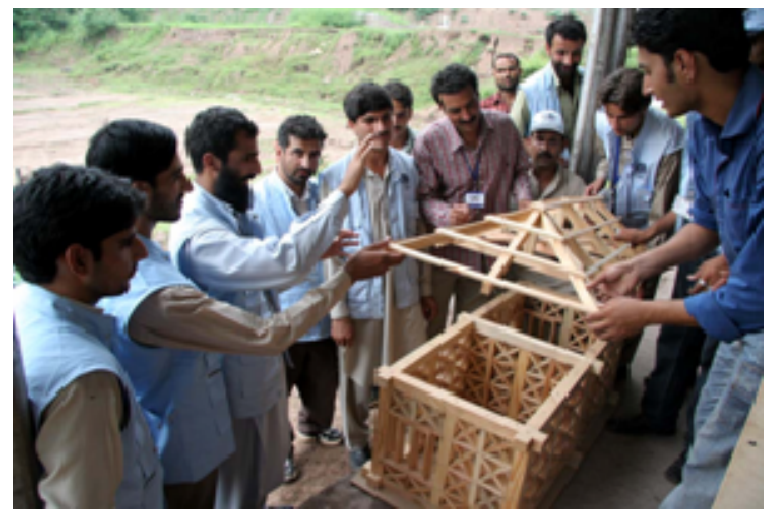

a) A demonstration model. providing training to communities and are involved in construction assessment and inspection processes.

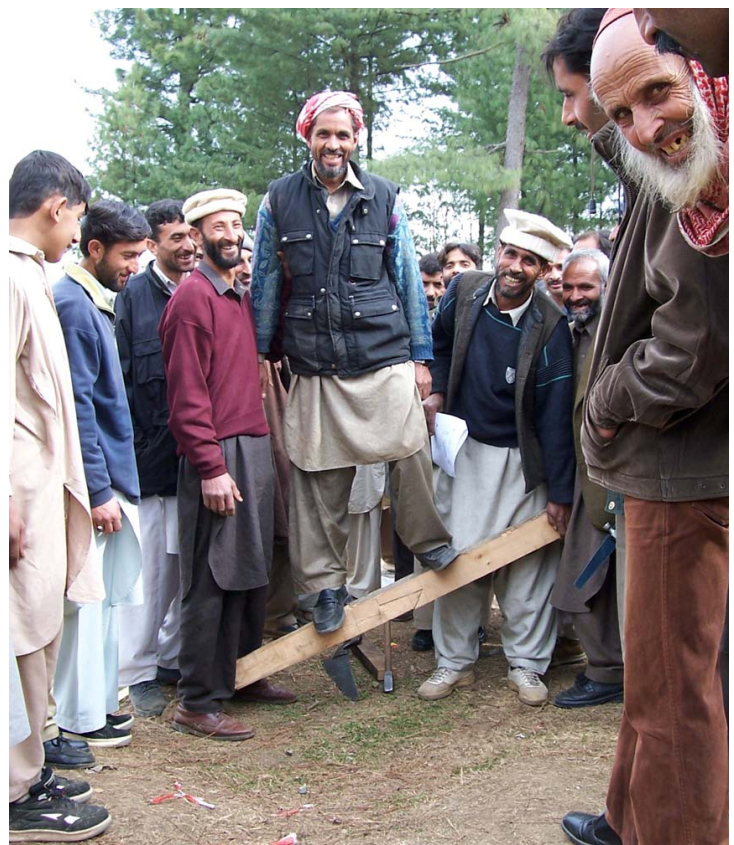

b) Testing strength of a timber joint (source: Kubilay Hicyilmaz).

Figure 10. Hands-on training.

\subsection{Construction guidelines}

The policy of owner-driven reconstruction was supported by developing a generic set of construction guidelines, posters, and checklists for different types of building (Figure 11). These are published in both Urdu and English and are available from UN-HABITAT. The expansion of the menu of construction options was incremental, responding to demands and practices in the field. These cover nominally reinforced masonry, reinforced concrete frames with confined masonry, in-situ concrete, and (most interestingly) Dhajji buildings. This traditional building type was originally restricted for reconstruction on the grounds that it is stone-in-mud mortar, and also because its use of timber in a mainly deforested country. However, the community had observed the excellent earthquake performance of the small number of existing Dhajji buildings and decided it was a safe and achievable technique for their new homes. The challenge was to get it into the ERRA-approved menu. UN-HABITAT collected evidence and references, documented practice, and proposed standards and specifications in order to convince ERRA and its donors that this should be considered a compliant construction option. The adoption of Dhajji as a permitted technique gave vital new options to those at high altitude. As it was a local building type, and local population had seen its excellent seismic performance, it has not been difficult to generate awareness of, or promote the use of, Dhajji construction. While the technique itself was little known, most carpenters and masons can readily learn it, as they are familiar with the materials and their use.

\subsection{Awareness raising activity}

For awareness raising of local community on seismic safety, dissemination of information, convincing the community for improved construction, various programmes were conducted which are outlined below:

- Orientation programmes: These one-day programmes were focused on the origin of earthquakes, the seismic hazard of the area, causes behind the building damage, and mitigation options and disseminated ERRA's guidelines along with distribution of posters and leaflets. Participants came from all walks of life such as students, professionals, Ulmas (religious leaders), prominent figures and other members of the community. Although a large proportion of the educational institutions and Ulmas could not be covered, those who have been oriented have played a good role in reconstruction. Now they believe that earthquakes are natural phenomena, man made them disasters, and by taking necessary steps damage can be reduced. UN-HABITAT also got Islamic scholars to make recordings on issues like taking responsibility to seek and use advice, and to exert moral pressure on builders who were knowingly taking shortcuts and putting lives at risk. These arguments are used in social mobilisation strategies.

As females are a large part of society, are more conscious about their family's safety, and often live at home most of the time, special orientation programmes on construction were conducted for them. In the disaster area, many males are away from home for work reasons. Many females supervise their house construction, and those who do not supervise at least have interaction with the artisans when providing them with lunch and tea. 


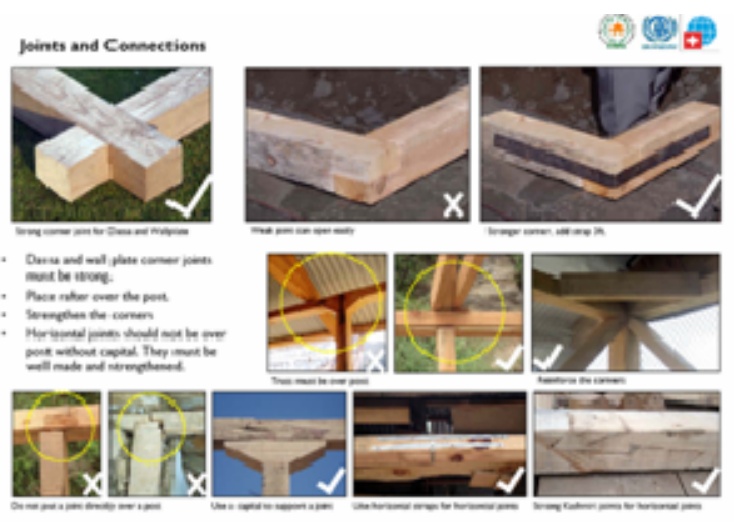

a) A Dhajji building guideline for inspectors

(this is a page from a laminated handbook for army inspectors to carry with them in the field, for them to identify and to explain to owners).

Figure 11. Sample of posters on Dajji-dewari.

- Print Radio programmes: Weekly radio programme were on air in which experts shared their knowledge on seismicity, potential seismic hazard, and measures and updates on construction processes. The radio shows were used to rapidly disseminate any updates or news, and to answer frequently asked questions from the field. In rural areas, radio has been a very effective medium.

- media: Local newspapers have been involved in awareness raising, and have played an important role in disseminating earthquake-resistant technology and policy issues.

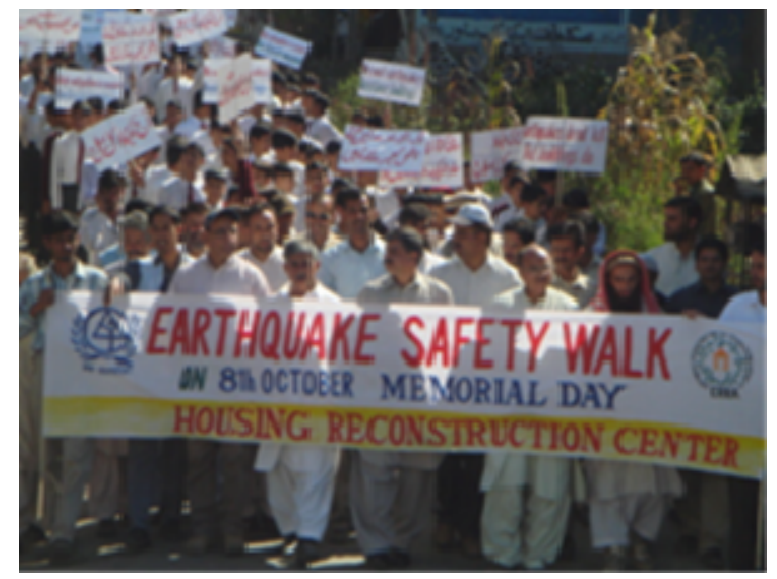

a) Earthquake safety procession.

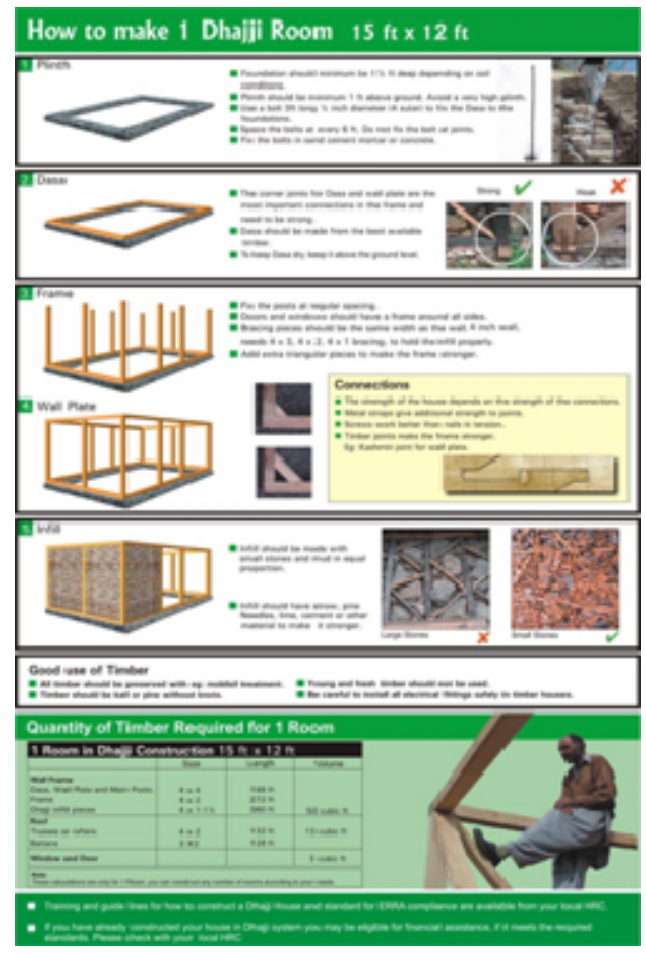

b) A poster on construction of Dhajji.
- Earthquake exhibitions and safety walks: HRC launched safety walks in which mostly students took part, and all segments of life participated. Students wrote play cards with different safety messages. These safety walks were combined with earthquake exhibitions (Figure 12).

- Debates on schools and universities: A programme of debate competitions was initiated in schools. Children were given topics regarding the occurrence of earthquakes and prizes were given..

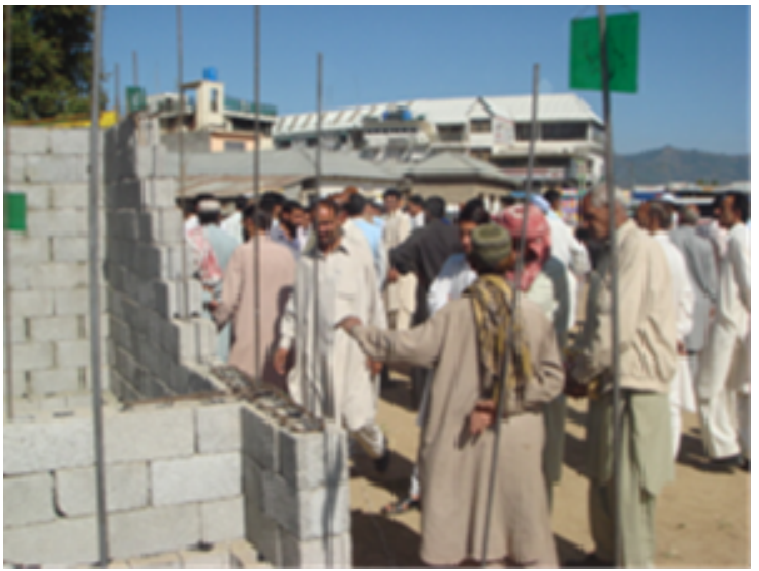

b) Full scale model demonstration. 


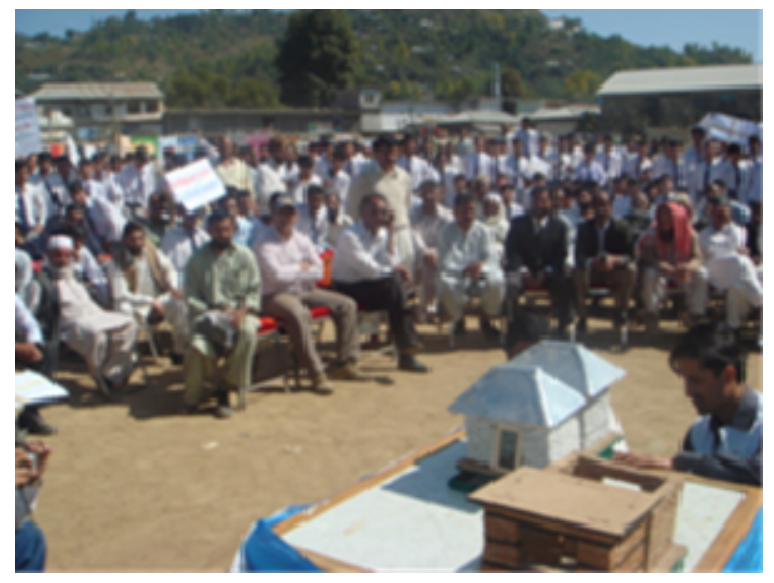

c) Shake table demonstration.

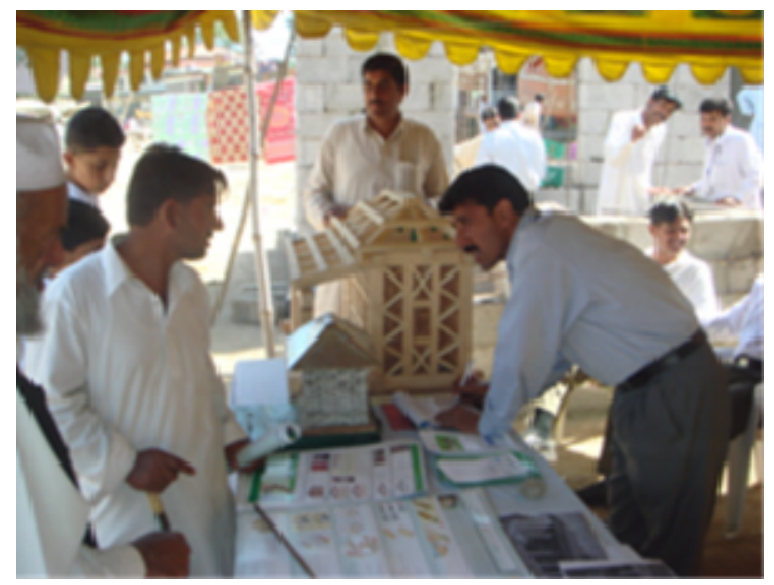

d) Advising and consultation.

Figure 12. Commemorating the Earthquake Day.

\subsection{Rate of reconstruction}

The rate of reconstruction has been extremely fast, after the initial delays with standards and the time required to put in place bank accounts, technical support and inspection mechanisms. The first building season in 2006 produced limited outputs - generally in high altitude areas where people started without any information on standards. Generally, most households managed to mobilise, resulting in a very high number of plinths completed to the ERRA specifications. During the second half of 2006, technical support and information dissemination had begun throughout the affected district, but with very few human and financial resources, and therefore with limited coverage and impact. From early 2007, the trends were clearer to see, including common defects, massive mobilisation of hollow-block production and use in some areas, and new construction types such as in-situ concrete walls or hybrids constructions. By the end of 2007, over 220,000 of the 250,000 households eligible for ERRA assistance had completed compliant plinths. Of those 220,000 , over 120,000 had completed their houses as far as

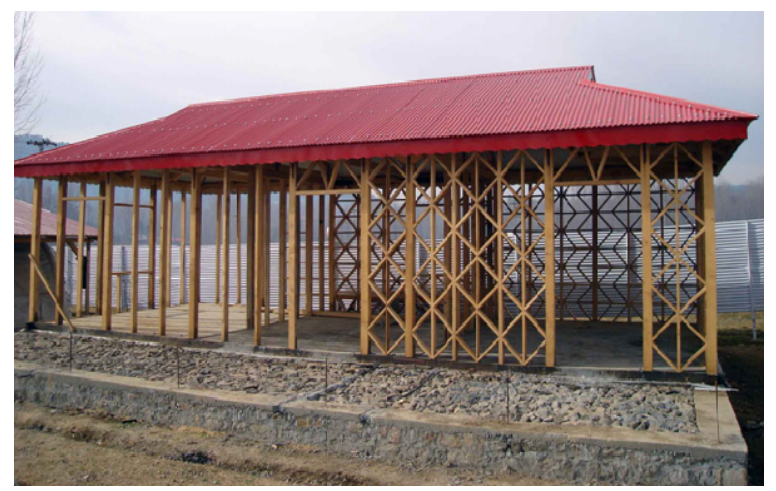

a) A Dhajji under construction. the lintels for inspection, and over $80 \%$ were compliant. This reflects a ramping up of activity by all involved during 2007: house owners, material suppliers, technical support and inspection.

Inspection accurately records the building types as stone, brick, block or timber frame to the level of individual household information. In addition, UN-HABITAT monitors trends in construction to plan for needs in training, advice and information products or demonstration. There are consistent patterns such as a general move away from flat roofs, either kachcha or reinforced concrete construction (except in specific areas), an almost universal use of a hipped roof rather than gables, retaining walls as the back wall of the house due to site constraints and a preference to move away from heavy construction. There are also regional preferences such as 150 $\mathrm{mm}$ hollow blocks in some areas, but solid blocks or in-situ concrete in other areas, due to transport costs, skill levels and skills availability.

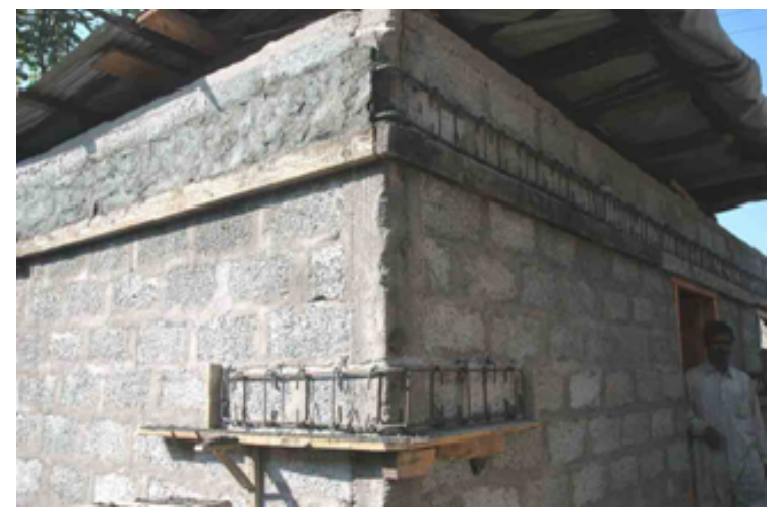

b) Implementing remedial measure for seismic safety.

Figure 13. Reconstruction. 


\section{LESSIONS LEARNT}

\subsection{Replication}

It is clear that most of the people do not have any idea of reconstruction, and wait for each other so that the first initiative is replicated by others. It has been observed that some NGOs built semi-permanent shelter, and people replicated them. For example, in some areas, a few people used timber posts in a block masonry house (Figure 6), and most of the people of that area then did the same. Some people used angle-iron posts in block masonry, and most of the people of that area followed that example. Similarly, in the area where someone first used seismic bands, most of the people in that area subsequently did the same. A large number of people invested both salvaged materials and financial resources in shelters, sometimes copying shelters built by NGOs. These shelters met immediate needs for the first winter, but are not appropriate long-term for the climate. Moreover, once there was an investment in the shelter, many did not wish to start again with a new building, preferring to incrementally improve the shelter. The lesson is that, after an earthquake, it is best to build some model houses at prominent locations with appropriate techniques before anyone else starts with wrong practices that will be replicated by the community.

\subsection{Owner and mason both need training/orientation simultaneously}

It has been experienced that, in order to synergise the efforts, the training for mason and owner should be mobilised simultaneously. If the mason does not know the safe techniques wanted by the house owner, the result is annoyance and frustration. On the other hand, if artisans know the techniques and the owner is not sensitized, the artisan training is wasted. Where both have been made aware, a synergy has been seen between craftsman and the house owner, resulting in better quality building.

\subsection{Policy delay}

The reconstruction policy was announced six months after the earthquake because of lack of preparedness for this scale of disaster. The delay resulted in a lot of gossip and caused confusion, frustration, and annoyance among the potential beneficiaries, particularly because of the approaching winter. Furthermore, there was delay in compliance standards being issued for the construction of houses. This further added to the confusion, although the policy was clear and consistent. In the absence of ERRA Standards, standards including halfheight walls were disseminated, and some reconstruction actors advised people to construct reinforced concrete columns to get a roof up before the next winter, and to deal with the infill walls later. By then, many others had started to construct, especially at high altitude, in order not to miss the 2006 building season. They used their past practice of dry stone walls, but to half height, with lighter construction above. Others used the past practice of wooden posts in masonry, but changed the masonry from stone to hollow concrete blocks which they considered safer, and which were relatively cheap and quick to construct. None of these buildings incorporated any earthquake-resistant measures, were considered noncomplying with ERRA requirements and thus not eligible for financial support.

\subsection{Emerging building types and compliance guidelines}

The initial ERRA standard was only for steel-reinforced masonry with sand-cement mortar and it put restrictions on the construction of stone masonry, though it was not viable in the first instance. Later on other building types were added and restrictions on construction in stone were relaxed. The expansion of the menu of construction options was incremental, responding to demands and practices in the field. However, the process of additions was perceived by some in the community, in technical support and in inspection, as an irritation or shifting of the goal posts. In future reconstruction scenarios, a wider range of options and a locally derived menu should be prepared from the outset, with an agreed process and schedule for review and revision.

\subsection{New materials. New technologies. Poor results.}

It was observed that many agencies, companies and institutions try to promote their products in the name of safe, fast construction - even though these might not stand the test. The regulatory system should be aware of this and should be able to regulate the market.

In 2006 most households managed only to construct a plinth. By early 2007 a new phenomenon became apparent - the proliferation of new, small-scale, hollow concrete block producers to meet the massive demand for blocks. This was not a consistent trend. It was most common in the areas of southern PAK. In the NWFP there was also an uptake of blocks but the preference was for solid blocks. The main reason may be the increased carriage costs for solid blocks due to their weight and the increased labour costs for block laying. Hollow blocks were considered a cheap and easy way to construct a wall. However, the quality of blocks severely deteriorated because of a lack of experience among the block manufacturers and no compliance with any quality control system. Most of all, neither they nor their customers understood curing and freshly-made blocks were sold and moved the same day due to the high demand. This has led to poor quality construction.

In addition those living in new, hollow concrete, block houses are realising the longer-term costs with respect to poor environmental performance, particularly because of high heating bills. However at the time they were constructing they were not aware of this factor. These buildings need now to be insulated, an additional financial burden on the building owner.

\subsection{Engineering advice and local circumstances}

When formulating policy, guidelines or advising, it is extremely important that the person-in-charge understand its implications, its acceptance from an affordability point of view and cultural acceptability. Under ERRA policy, a restriction was put on the use of stone masonry and insisted on the use of cement-based mortar and steel reinforcement for building construction. These were not feasible options because of the high cost of transport of cement, sand and steel. In many areas there was not any alternative to stone. When advising site selection the guidelines advised that the distance between house and background should not be less than the height of the house, if the house were to be constructed on a slope. Compliance with this advice was not possible in many areas because of a lack of space.

\subsection{Quality control issues}

With increasing pressures on the construction market deterioration in material quality and construction skills was observed. It became obvious that it is not possible for owners to achieve good results and the desired earthquake resistance if they are not protected by regulatory standards with regard to key materials. The role and responsibilities of owners, technical support and government developed or improved in 
response to problems or needs during this process, but could have been better anticipated and planned. For future disasters, at least the role of governments with regard to policy, standards and regulatory frameworks needs to be prepared.

During the process, UN-HABITAT advocated better regulation of the material supply and the fabrication sector and assisted through training and information both block makers and house owners. As a consequence block testing was introduced by ERRA and block standards improved significantly in most of the areas. The lesson is: if committed regulatory systems are in place, they work.

\subsection{Remedial measures}

Due to the delay in the confirmation of standards many who started early construction found themselves non- compliant with basic safety standards and thereby failed to be certified for approval for financial assistance. UN-HABITAT and its partners have put considerable effort into identifying the common and serious defects and providing solutions for house owners to carry out additional remedial works to improve the safety of those houses. These remedial measures are intended for new construction, not damaged construction, but could be used for retrofitting any substandard buildings. The measures have all been tested on site to check and improve their practical application, to train the engineers and artisans and to generate information materials. Site testing also helped to ascertain the time, material, skill level and costs involved, all of which are key criteria in the process of convincing owners to carry out the additional work.

The significant focus on remedial measures has meant an increased knowledge and skill level among not only the engineers, but also the artisans. It has also meant that an active diagnosis and response capacity has been required, as is the ongoing generation and testing of solutions, and the need to consider not only engineering principles, but also cost benefit analysis. This means not only equipping the technical support team with a curriculum and training skills, but also with investigative skills and improved judgement. Basically this means not only equipping them with a few answers, but with the right questions. This is an important consideration in the development of technical support capacity for a fluid and fast moving reconstruction programme which is indeed driven by owners and the field and not by predetermined assumptions of the engineering community.

\subsection{Dynamism in curricula}

It is important not to assume that it is adequate to rely on a fixed curriculum for technical training, without reviewing the field practices of those who have participated in training and the very large number of other artisans who have not received training. They may have specific patterns of malpractice, such as no mortar in vertical joints, levelling mortar beds flat in stone work and letting it set before laying the next course, reducing the bond. The diagnosis of workmanship issues and shortcomings in interpretation of new technology needs to be used to evolving the curriculum, or to devise supplementary activities to reinforce it.

\subsection{Orientation to women}

It has been observed that women are more dedicated, responsible and sensitive to achieving quality construction. In a few places, masons were complaining that they interfere with their work. This means that these women were committed to see what they had learned was implemented in their houses.

\subsection{Decentralization and CBOs/ NGOs}

Some of the good lessons learnt during the reconstruction and rehabilitation programme are the benefits of decentralisation of all the activities, assisting people at their home sites, maintaining livelihoods and community support networks and enabling them to rebuild early.

Community-based and non-government organizations (CBOs and NGOs) played an effective role in the overall reconstruction and rehabilitation programme by systematically mobilizing the community. As these organisations come mostly from within local communities, they have a better understanding of need and supply and penetration in the community. They also better understand the sensitivities and cultural aspects. They played an effective role in information dissemination and oriented and mobilised the community. It is hoped that these $\mathrm{CBOs} / \mathrm{NGOs}$ will help the sustainability of seismic safety in rural areas.

The greatest contribution to sustainability is the widespread participation in responsibility for safer buildings by not leaving it to a few contractors (as happened in BAM in Iran) or to NGOs (as in Gujarat, India), or to the government. Those who had to learn how to comply with standards to get their financial assistance were the owners themselves and their masons. This means that over 500,000 people had to actively seek information, training or advice on seismic-resistant construction, whether formally from a HRC, or informally from a neighbour, or by visiting a model house. From this wide base of awareness and knowledge there is a greater chance of long-term adoption and replication.

\subsection{Urban - Rural issues}

It is interesting to note, the strategy which worked well in rural reconstruction could not help much in the urban sector because of some obvious issues. These issues are discussed here.

The earthquake of 8th October 2005 affected principally 4 towns, Muzaffarabad, Bagh, Rawalakot and Balakot. Before the earthquake, these towns played a vital role in the social and economic development of the affected areas. The ERRA decided to take the opportunity to 'build back better' by replanning, reorganizing and rebuilding these four main towns into better functioning and more inclusive urban centres and building the capacity of the institutions responsible for urban management, including disaster management.

Master planning exercises were conducted in the 4 urban centres and urban investment projects, such as water supply and water treatment, roads and electrical installations have been planned and will be implemented. Under ordinary circumstances the capacity of the local district and state / provincial governments to coordinate this ambitious rebuilding agenda would have been limited. Post-earthquake, this capacity is severely diminished due to a significant loss of human resources and physical infrastructure.

When developing master plans, the community were consulted in the process, but the final results were not necessarily widely understood and most people do not know the status of the plan or proposed new infrastructure work. 
While the master planning involved extensive inputs, there has not been sustained or sustainable technical support to the local authorities. The focus has been on public infrastructure works and not on private reconstruction or urban management.

There is a general lack of interface between community and the Authority. There is no plan to assist the private sector to understand what is planned, or to optimise the investment in infrastructure, to make localised adjustments to the master plans, to promote building standards, to provide technical advice, to advice owners of adjoining sites on joint plans, to advise owners in red zones, to assess submissions, to carry out inspection. While there is a code for new construction there is no support or guidance for retrofit of the large number of partially damaged houses.

Balakot town was the most heavily damaged, and after assessments the technical conclusion was that the location was highly hazardous and people should not be allowed to reconstruct there. A number of alternative sites were considered to relocate the population. The Government has tried to balance safety with proximity, and has invested very heavily in preparing the site and providing services. However, as is usually the case with relocation, there is limited uptake of the plots and considerable resistance by the community to having to move. The old town is now heavily populated with prefabricated shelters and the commercial area is being incrementally rebuilt.

For all 4 towns there was a ban on reconstruction until the Spring of 2007, subject to confirmation of masterplans. Compensation has not yet been agreed for land acquired for the masterplan. While financial assistance was disbursed, most households were unable to start construction, and have used up resources in high rents and other costs. At all stages there have been delays in decision making and implementation, debris was not removed for over 1 year before starting new infrastructure contracts. The construction of expensive temporary shelter facilities starting almost 3 years after the earthquake, is in many cases another delay and pre-empts and constrains permanent reconstruction as well as absorbing the funds available.

The cost of reconstruction of rural houses, starting in 2006 was approximately $10 \$$ per $\mathrm{sq} \mathrm{ft}$, constructing single storey load bearing masonry. Most households also received CGI sheets as humanitarian support for the first winter, and had additional land available for joint families to construct separate houses. On the other hand urban families are starting 2 years later, with escalated costs of materials, without donated materials and without access to land for joint families to construct separately. Urban houses are likely to be multi storeyed with RCC roofs. These factors combined are resulting in average construction costs of $30 \$$ per sq $\mathrm{ft}$. Although the system has theoretically been equitable for urban and rural housing, with the same financial assistance, in practice households have faced different challenges. There is no mechanism of soft loans.

The system of tranche disbursement subject to compliance at stage inspection has proven effective in rural housing, but without similar leverage and very low capacity in local authorities, it appears unlikely that new urban housing will be reconstructed to safer standards.

\section{CONCLUSION}

The paper has discussed the challenges of reconstruction after the 8th October 2005 Kashmir Earthquake, the policy directives and strategy to tackle the challenges, the tools devised for awareness raising, the experience of reconstruction and the impediments. What has been observed is that in such a massive disaster where there is an informal construction regime, the owner-driven approach is the most suitable to be supported by the formal sector.

This approach has helped the building owners to adopt their cultural identities in the construction, and continue traditional construction with incorporation of aseismic features. It has expedited the construction pace and equity, and the sustainability of the process in the rural areas. However, it should be noted that same could not be the case in urban reconstruction due to different socio-economic regime, legislative system, land and planning issues. We believe that the lessons learnt are equally applicable around the world, particularly in developing countries, and for the reduction of other disaster risks as well.

\section{ACKNOWLEDGEMENTS}

The first author expresses his gratitude to NSET-Nepal for giving him the opportunity to work as a team leader for Capacity Building for Earthquake-Resistant Construction under the funding of UNDP, Pakistan and later as a team member under funding of UN-Habitat.

We express our deep gratitude to the people of PAK and the NWFP for giving us access to buildings and construction sites, for the opportunity to work for them, and for their generosity. We are thankful to Dr Richard Sharpe for editing/ reviewing the paper. The views expressed here are the authors' own views.

\section{REFERENCES}

Bilham, R., Gaur, V. K. and Molnar, P., (2001). Himalayan Seismic Hazard, Science, 293, 1442-4.

Bothara, J. K., (2007). Social Intervention Required for Sustainable Seismic Safety after the Pakistan Earthquake, Paper\# 049, Conference Proceedings of Pacific Conference 2007, Singapore, 5-7 December,

ERRA, (2006a), Strategy Document Rural Housing Construction, Building Back Better: Rural Housing Reconstruction strategy of Earthquake hit districts in NWFP and AJK, Earthquake Reconstruction and Rehabilitation Authority, Pakistan, www.erra.gov.pk/report/Rural\%20Housing\%20final\%20 strategy-20\%20Apr $\% 202006$

USGS,

http://earthquake.usgs.gov/eqcenter/eqinthenews/2005/us dyae/ 